1

2

3

4

6

7

8

9

21 Number of figures: 7

22 Number of tables: 3

23 Appendices: 1 sunbirds

Total word count: 6379

\title{
Nicotiana glauca a product of pollinator-mediated selection? \\ Is variation in flower shape and length among native and non-native populations of
} Arístides Cocucci ${ }^{1}$, Anna Traveset $^{3}$, Federico Sazatornil $^{1}$ and Valeria Paiaro ${ }^{1 *}$ Macarena García ${ }^{1}$, Santiago Benítez-Vieyra ${ }^{1}$, Alicia Noemí Sérsic ${ }^{1}$, Anton Pauw ${ }^{2}$, Andrea

1- Instituto Multidisciplinario de Biología Vegetal (IMBIVCONICET), Universidad Nacional de Córdoba, Av. Vélez Sársfield 1611, C.C. 495, 5000 Córdoba, Argentina

2- Department of Botany and Zoology, Stellenbosch University, Private Bag X1, Matieland 7602, South Africa

3- Instituto Mediterráneo de Estudios Avanzados (CSICUIB), C/ Miquel Marquès, 21 - 07190 Esporles, Mallorca, Balearic Islands, Spain

*corresponding author: e-mail: vpaiaro@gmail.com

Running title: Flower shape and length in native and non-native pollination environments

Keywords: geometric morphometrics, hummingbirds, phenotypic selection, self-pollination, 
Due to drastic changes in pollinators between native and invaded habitats, we might expect that pollinator-mediated selection on floral traits of alien plants differ from that in their native ranges.

27 Here, through geometric morphometric tools and phenotypic selection analyses, we examined

whether adaptation in flower shape and length occurred in Nicotiana glauca as a response to pollinator selection in contrasting pollination environments. We assessed populations of this plant species in the native range (South America), where plants depend on hummingbird pollination, and in two invaded areas, one where sunbirds act as pollinators (South Africa), and another where nectar feeding birds are absent and reproduction is entirely by autonomous self-pollination (Mallorca, Spain). Corolla length and shape varied significantly among pollination environments. Non-native sites were less variable and their range of variation fell within the native range of variation. Flower length in native populations and in a South African population matched the bill length of their respective pollinators. In contrast with the straight floral tubes in the native range, both non-native areas had significantly curved tubes. Curvature may improve the fit with the curved bills of sunbirds in South Africa (versus straight beaks of hummingbirds) and may enhance selfpollination in Mallorca, but this similarity between invaded areas may equally be due to drift and a shared colonization route. We found spatial variation in selection acting on corolla length but not on corolla shape. Overall, selection patterns were not consistent with floral trait variation. Although some results are consistent with both drift and selection, our study suggests that population divergence in flower shape and length is more likely the result of long-term diversifying pollinatordriven selection, which is difficult to detect by studying a single selection event. 


\section{Introduction}

48 Species introduction into new environments generally involves drastic changes in the selective 49 regime, which can lead to adaptive evolution (Sakai et al 2001; Murren et al 2009; Molina50 Montenegro et al 2011; Westley 2011; Colautti and Lau 2015). Simultaneously, the reduction in 51 population size during the colonization event will favour genetic drift and will reduce genetic 52 diversity of introduced plant populations, limiting the possibility of adaptive evolution of traits 53 under new ecological conditions (Charlesworth 2003; Dlugosch and Parker 2008; Charlesworth et al 2009; Colautti et al 2010). The success of invasive species may to some extent be determined by their capability to adapt to new environments (Colautti and Lau 2015).

Pollinators, which are one of the main agents of selection on floral traits (Caruso et al 2019), may differ substantially in their abundance and identity between native and non-native habitats (Traveset and Richardson 2014; Jiménez-Lobato et al 2018; Issaly et al. 2020). Alien animalpollinated plants, even those highly specialized in their native range, may respond by adapting to functionally similar or completely novel pollinators in non-native areas (Richardson et al 2000; Geerts and Pauw 2009; Traveset and Richardson 2014). They may also change their mating system or rely on some kind of asexual reproduction if suitable pollinators are lacking in the new environment (Richardson et al 2000; Ollerton et al 2012; Traveset and Richardson 2014; JiménezLobato et al 2018; Issaly et al. 2020). Phenotypic selection studies have provided a valuable snapshot of spatial variation in selection on floral traits across populations with different pollinator faunas (e.g., Nuñez-Farfan and Schlichting 2005; Kingsolver and Pfennig 2007; Gómez et al 2008).

7 Geographic variation in pollinators, the so-called pollination climate, may result in concomitant spatial variation in the nature of selection affecting floral traits, especially if pollinators differ in 
morphology, foraging behavior or flower trait preferences (Gómez and Zamora 2000; Herrera et al 2006; Moeller 2006; Gómez et al 2008; Nattero et al 2010a,b).

Selection in new habitats may occur not only in response to the presence of new pollinators but also in response to their absence (Hierro et al 2005). When pollinators are scarce or absent in the new range, selection would favor characters that enhance opportunities for selfing in order to ensure reproduction (Fenster and Ritland 1994; Moeller 2006). Morphological changes that are associated with selfing include reduced herkogamy (Takebayashi et al 2006; Bodbyl-Roels and Kelly 2011), bent or severely crumpled corolla tubes (Schueller 2004) and a reduction in flower size, which can be the result of differential selection on resource allocation to attractiveness function (Lloyd 1987; Charlesworth and Morgan 1991; Fishman and Willis 2008).

Our understanding of how invasive plants can adapt to changes in pollinators is limited. This is an important gap in our knowledge because pollinator environments have drastic implications for plant reproduction and fecundity, and in turn for long-term evolution of invasive species. However, very few studies quantified selection on floral traits in both native and nonnative populations (but see Murren et al 2009; Jiménez-Lobato et al 2018). These kinds of studies are crucial to identify traits under selection in invaded environments and to determine how selection may differ between invaded and native ranges, which, in turn, may be important to determine invasion rate and impacts on native ecosystems (Colautti and Lau 2015).

Nicotiana glauca R. Graham (Solanaceae) is an ornithophilous South American shrub (Goodspeed 1954) that successfully invaded semi-arid regions around the world with different pollinator environments (Ollerton et al 2012; Issaly et al 2020). Here, we studied floral shape and length and their phenotypic selection in the native range, where plants depend on hummingbirdpollination, and in two invaded areas, one where sunbirds act as pollinators, South Africa, and 
another where nectar feeding birds are absent and reproduction is entirely by autonomous selfpollination, the Balearic island of Mallorca (Issaly et al 2020). Previous studies on N. glauca found high variation in corolla length associated with bill length of hummingbird pollinators across the native range (Nattero et al 2011) and among non-native populations in the USA (Schueller 2007). In addition, another study showed that pollinator-mediated phenotypic selection potentially shaped corolla length in several native populations (Nattero et al 2010a). Finally, a recent study in this species found that increased self-pollination ability in Mallorca, a non-native environment without pollinators, was not associated with a reduction in anther-stigma distance (Issaly et al 2020). Instead, this study proposed that a narrow and curved floral tube could favor pollen deposition on the stigma when the corolla and stamens detach from the gynoecium, bringing about delayed selfpollination (sensu Lloyd and Schoen 1992) in this invaded area. Differences in pollinator morphology in different areas may also be a factor that mediates selection on flower shape of $N$. glauca (Gómez et al 2008; Benítez-Vieyra et al 2009). Birds that hover while feeding, including most hummingbirds, generally have straight bills, whereas birds that perch while feeding, such as the Old World sunbirds, have bills that are decurved to some extent (Paton and Collins 1989), because they probe in an arc motion from a fixed perching position (Westerkamp 1990; Temeles et al 2009).

We hypothesized that changes in flower shape and length of $N$. glauca occur in native and non-native ranges as a response to selection by the different pollination environments (i.e., native hummingbird-pollination, non-native sunbird-pollination, and non-native without pollinators). Specifically, we expected to find significant levels of phenotypic differentiation in corolla length and shape across pollination environments. In relation to flower size, we expected the smallest (i.e. shortest and narrowest) corolla tubes in non-native areas without pollinators, and differences in 
115 flower length between populations whose main pollinator varies in bill length both in the native

116 and South African ranges. Regarding flower shape, we expected to find straight corollas in the

117 native range and curved corollas in both non-native pollination environments. Finally, we expected

118 that patterns of pollinator-mediated phenotypic selection would be consistent with floral trait

119 differentiation across populations.

121 Material and Methods

122 Study species and sites

123 Nicotiana glauca is a fast-growing shrubby tree native to central Argentina and Southern Bolivia 124 (Goodspeed 1954). It has been widely introduced, either deliberately as ornamental, or 125 accidentally, and has become a weed in the subtropical regions of four continents (Cronk and Fuller 126 1995). The species is listed in the Global Invasive Species Database 127 (http://www.issg.org/ase/welcome/) and is considered invasive in regions such as Europe and 128 South Africa.

Almost all year round, in both the native and non-native range, plants of $N$. glauca produce many inflorescences that bear numerous flowers, which open throughout the day and last about 34 days. Flowers have long (30-57 $\mathrm{mm})$ and wide $(6-11 \mathrm{~mm})$ tubular corollas with a reduced corolla

$132 \mathrm{limb}$ (Nattero et al 2011). The corolla is greenish-yellow when young, changing to bright yellow 133 when aging. Some populations in Argentina have colour polymorphism including dark red, reddish 134 yellow and yellow morphs (ANS, AAC and VP, pers. obs.). Anthers reach the corolla tube opening 135 and the stigma may be as high as or a little higher than the anthers (Issaly et al 2020). Flowers are 136 scentless and produce large amounts (ca. $20 \mu \mathrm{L}$ ) of low concentration (ca. $25 \%$ sucrose) nectar 
137 (Galetto and Bernardello 1993). The two-valved dehiscent capsules contain hundreds of tiny seeds.

138 Propagation may also occur clonally.

In its native range, $N$. glauca is visited by different hummingbird species assemblages depending on the geographic location of the populations (Nattero and Cocucci 2007; Nattero et al 2010a, 2011). Outside the Americas the species interacts with different bird pollinators, such as sunbirds in South Africa, or set seeds exclusively by selfing in areas where nectar feeding birds are absent, such as the Mediterranean Basin (Geerts and Pauw 2009; Ollerton et al 2012; Issaly et al 2020). Despite their typical perching behavior, Old World sunbirds, especially the malachite sunbird, Nectarinia famosa, must often hover to feed from the flowers of N. glauca (Geerts and Pauw 2009). The species is self-compatible throughout the native and non-native range, although in pollinator poor areas plants have a much higher capability for autonomous self-pollination than elsewhere (Issaly et al 2020). Conversely, pollination by hummingbirds and sunbirds increases reproductive success of plants both in native and in South African areas, respectively (Geerts and Pauw 2009; Issaly et al 2020).

To compare the different pollination environments of $N$. glauca, we studied three native populations, two in Argentina and another in south Bolivia, two non-native populations in South Africa, and two non-native populations on the island of Mallorca (Balearic Islands, Spain; Table 1). The first records of $N$. glauca were in 1884 for South Africa (Bromilow 2001) and between 1827 and 1879 for the Balearic Islands (Moragues and Rita 2005). Populations within each region were separated by at least $2 \mathrm{~km}$. Study populations were located either in semiarid naturally 157 disturbed (riverbanks or alluvial sediments) or artificially disturbed areas (roadsides, farmlands and abandoned quarries). We carried out samplings during spring and summer (in both hemispheres) 159 between 2012 and 2014. 
Pollinator assemblages

162 To determine pollinator assemblages in the study populations, we complemented previous detailed

163 studies (Geerts and Pauw 2009; Nattero et al 2011; Ollerton et al 2012) with additional

164 observations. We performed observations with close focusing $8 \times 40$ binoculars during 10-15

165 periods of $20 \mathrm{~min}$ from 7:00 to 14:00 h on two sunny days per population. We also surveyed the

166 two Mallorcan populations for nocturnal visitors from 19:00 to 22:00 h on one evening each.

167 Pollinator visitation rate analyses for the study populations were published elsewhere (Issaly et al

168 2020), and here we only present a summary of pollinator composition and relative visitation

169 frequencies (Table 2). We took into account only legitimate visits (i.e. those that touched floral

170 fertile parts), and included both hovering and perching visits in the case of sunbirds. For each

171 observed hummingbird and sunbird species, we obtained mean bill length (i.e., exposed culmen

172 taken from the nostril to the end of the bill) in the respective geographic provinces of the study

173 sites, from Nattero et al (2011) and from the South African Bird Ringing unit (SAFRING) database,

174 respectively.

175

176

\section{Floral traits}

177 We labeled between 43 and 100 plants in each population (Table 1) and collected three flowers per 178 plant. We photographed flowers laterally with a reference scale using a Nikon Coolpix 5400 179 camera, following a standardized protocol, with the camera's axis perpendicular to the corolla tube 180 surface. We quantified corolla tube shape by means of geometric morphometrics (Bookstein 1997; Zelditch et al 2012). For each flower of $N$. glauca, 18 coplanar landmarks along the corolla tube were defined (Fig. 1). The landmarks 1, 3, 8-11, 16 and 18 represent the limits between different 
183 kinds of tissues or anatomical structures (i.e., corolla limb-corolla tube, corolla tube-calyx, and 184 calyx-pedicel). The landmarks 2, 6, 7, 12, 13 and 17 were points of minimum or maximum 185 curvature. The remaining four landmarks $(4,5,14$ and 15) were semilandmarks, a series of 186 locations to capture the homologous curved outlines of the corolla-tube between the remaining 187 landmarks (Gunz and Mitteroecker 2013). We obtained landmark configurations from each 188 individual using the program TpsDig ver. 2.16 (Rohlf 2010). We performed a generalized 189 Procrustes analysis on landmark coordinates using the program MorphoJ (Klingenberg 2011). This 190 analysis involves three steps: (1) translation of the landmark configuration of all objects so that 191 they share the same centroid; (2) scaling of the landmark configuration so that they have the same 192 centroid size; and (3) rotation of the landmark configurations to minimize squared Euclidean 193 distances between homologous landmarks (Zelditch et al 2012). In this way, the data matrix of 194 Procrustes coordinates only retains shape information. After superimposition, we averaged 195 landmark configurations from flowers of the same individual. Subsequently, to summarize flower 196 shape variation, we performed a Principal Component Analysis (PCA) on the Procrustes 197 coordinates using the MorphoJ software (Klingenberg 2011). We visualized morphological 198 changes along PCs axes using the transformation grids from the MorphoJ program (Klingenberg 199 2011).

200 Using CoordGen 8 software (Sheets 2017), we obtained linear measures from landmark 201 coordinates: the distance between landmark 1 and 8 and the distance between landmark 11 and 18 .

202 We then obtained corolla tube length as the average between both distances. 203

204 Fitness measures 
205 We obtained fruit set and seed number per fruit as female fitness measures. Fruit set (proportion of 206 pollinated flowers) is an estimate of pollination intensity, while the mean number of seeds per fruit 207 estimates the quality of mating (Nattero et al 2010a). For each plant, we marked five branches, 208 recorded the total number of flowers per branch and identified them by painting the persistent calyx 209 with waterproof paint. After 20-30 days, we counted the number of fruits produced and then 210 estimated fruit set per plant as the proportion of painted flowers setting fruits. To determine seed 211 number per fruit, we collected approximately 10 mature fruits per plant shortly before capsule 212 opening and stored them in paper bags until fruits opened. We weighted a known number of seeds 213 (ca 200 seeds) and the total seeds collected per plant (all fruits together) with a precision balance 214 (Sartorius CP224 S, accuracy $=0.1 \mathrm{mg}$ ), and estimated the number of seeds per fruit per plant $(S n)$ 215 as:

$$
\mathrm{Sn}=\mathrm{Ss} \times \mathrm{Tw} \times \mathrm{sw}^{-1} \times \mathrm{Fn}^{-1}
$$

217 where $S s$ is the number of seeds in the sub-sample, $T w$ is the weight of all seeds contained in the 218 fruits, $s w$ is the weight of the seed sub-sample, and $F n$ is the number of fruits collected per plant.

\section{Analysis of phenotypic variation}

221 To assess differences in floral traits among pollination environments we conducted a nested 222 analysis of variance (ANOVA) and a Procrustes nested analyses of variance for corolla length and 223 corolla shape variables, respectively. In both cases, hierarchical levels considered were pollination 224 environment (hummingbirds, sunbirds and no pollinators), populations within pollination 225 environments, plants within populations, and flowers within plants (this level was used as residual 226 variance). In addition, we performed an ANOVA on corolla tube length to detect between- 
227 population differences in this floral trait, using mean values of corolla length from each plant. We

228 conducted these analyses using the R 3.6.3 software ( $\mathrm{R}$ Core Team 2020).

229

230

Analysis of phenotypic selection

231 We performed separate phenotypic selection analyses for each population and fitness measure (fruit

232 set and number of seeds per fruit). To estimate selection gradients, we used multiple linear

233 regressions following the model proposed by Lande and Arnold (1983). Selection gradients

234 estimate the magnitude and direction of selection on a specific trait or combination of two traits

235 independently from the indirect effect of other traits (Lande and Arnold 1983; Brodie et al 1995).

236 Linear selection gradients $\left(\beta_{\mathrm{i}}\right)$ indicate that extreme phenotypes (minimum or maximum values)

237 attain highest reproductive success. Non-linear selection gradients indicate stabilizing or disruptive

238 selection on one trait $\left(\gamma_{\mathrm{ii}}\right)$ or correlational selection on a pair of traits $\left(\gamma_{\mathrm{ij}}\right)$. Models included the first

239 two principal components of flower shape and flower tube length as phenotypic measures. We used

240 fruit set and number of seeds per fruit as estimates of reproductive success.

241 Because regression analyses residuals departed from normality, we applied bootstrap to

242 estimate the significance of selection gradients (Dixon 1993; Benitez-Vieyra et al 2012), following

243 the procedure detailed in Palacio et al (2019). We generated 10,000 bootstrap samples from the

244 original data set. We used selection gradients estimated after each bootstrap to obtain their

245 frequency distributions. We considered a selection gradient was significant if its bias-corrected

$24695 \%$ confidence percentile interval did not include zero. We used the boot package of R 3.6.3

247 software to perform the bootstrapping and estimate the 95,99 and $99.9 \%$ confidence intervals. We

248 provided selection gradient estimates and confidence intervals as supplementary material (S1). 
Because the Lande and Arnold's approach represents a linear or quadratic approximation

250

251

252

253

254

255

256

257

258

259

260

261

262

263

264

265

266

267

268

269

270

271 to the relationship between fitness and a given trait or combination of traits (Brodie et al 1995), interpretation of selection gradients may be misleading, especially when a combination of directional and quadratic selection occurs (Mitchell-Olds and Shaw 1987). Hence, we used generalized additive models (GAMs) to depict the relationship between phenotypic traits and fitness, avoiding a priori assumptions about the shape of this relationship. We used binomial error structure for models where fruit set is the response variable. Binomial distribution is the proper choice when response variables is a proportion (Warton and Hui 2011), as it represents the number of times some outcome (in our case the fruits) occurs out of $n$ trials (the flowers, which were either form fruit or not). We used penalized quasi-likelihood estimation, because previous examination detected overdispersion (Zuur et al 2009). Form models where the response variable is the number of seeds per fruit we used negative binomial error structure and maximum likelihood. This distribution is commonly used for count data and, contrarily to Poisson distribution, it can deal with overdispersion (Zuur et al 2009). When we detected significant selection gradients on a trait (either $\beta_{\mathrm{i}}$ or $\gamma_{\mathrm{ii}}$ ), we plotted the relationship between each floral trait and fitness, as estimated from a multivariate GAM, fixing covariates at their mean value. If we detected significant correlational selection gradients $\left(\gamma_{\mathrm{ij}}\right)$, we used GAMs to depict the selection surface between those traits and fitness. We obtained bayesian standard errors of prediction according to Wood (2017).

Finally, we used analyses of covariance (ANCOVAs) to examine whether selection patterns (linear, quadratic and correlational) varied significantly among populations, testing the effect of the interaction between the population and phenotypic traits on fitness (Maad and Alexandersson 2004). 


\section{Results}

\section{Pollinator assemblages}

274 Hummingbird species composition of the pollinator assemblages differed among the native 275 populations. At Piedra Pintada, Patagona gigas was the most frequent pollinator followed by 276 Sappho sparganura and Chlorostilbon lucidus; at Tupiza, P. gigas was the only pollinator species, 277 and at Embarcación, S. sparganura was the only observed species (Table 2). The bill of these 278 hummingbirds is straight (Fig. 2a-c) with length ranging from $19.37 \mathrm{~mm}$ for Chlorostilbon lucidus 279 to $44.30 \mathrm{~mm}$ for Patagona gigas (Table 2). In both South African populations the pollinator assemblages comprised three sunbirds species (Nectarinia famosa, Cinnyris fuscus and Cinnyris chalybeus), but differing in abundance between sites: $N$. famosa was the most frequent species in of these sunbirds is curved (Fig. 2d-f) with length ranging from $18.23 \mathrm{~mm}$ for C. fuscus to 35.83 mm for $N$. famosa (Table 2). In the Mallorca populations, we observed only the hummingbird hawkmoth (Macroglossum stellatarum) as an occasional legitimate visitor of $N$. glauca flowers.

\section{Phenotypic variation in flower traits}

288 Procrustes nested analyses of variance showed significant differences in flower shape among environments with different pollinators (hummingbirds, sunbirds, and without pollinators; $\mathrm{F}_{2,1535}$ $=191.92, \mathrm{P}=0.001)$, among populations within pollination environments $\left(\mathrm{F}_{4,1535}=169.35, \mathrm{P}=\right.$

291
$0.001)$ and among individuals within populations $\left(\mathrm{F}_{7,1535}=3.85, \mathrm{P}=0.001\right)$.

The PCA performed with the Procrustes coordinates of the corolla yielded 32 PCs. The first two PCs accounted for $70 \%$ of the total variance in shape. The first, PC1 axis (57.53\% of variation), was associated with changes in flower width. Low values of PC1 correspond to wide floral tubes 
295

296

297

298

299

300

301

302

303

304

305

306

307

308

309

310

311

312

313

314

315

316

317

and high values correspond to narrow floral tubes (Fig. 3). This PC showed high variation within the native hummingbird-pollination environment. Plants from Embarcación and Tupiza showed high PC1 values (i.e., narrow flowers), while plants from Piedra Pintada reached the lowest PC1 values (i.e., the widest flowers). In addition, the latter native population showed the highest intrapopulation variation in this PC. Plants in the non-native sunbird-pollinated environment showed intermediate $\mathrm{PC} 1$ values and plants in the non-native environment without pollinators showed high PC1 values (i.e., narrow flowers). The PC1 variation range across the native environment encompassed variation ranges of both non-native pollination environments.

PC2 axis (12.63\% of variation) was associated with changes in both flower curvature and flower width. The PC2 variation ranges differed between the native and non-native pollination environments. Plants in the native hummingbird-pollinated environment showed low PC2 values corresponding to straight and wide corolla tubes, while those in both non-native pollination environments (i.e., sunbird-pollinated and without pollinators) showed high PC2 values which correspond to curved and narrow corolla tubes.

We detected significant differences in corolla tube length among different pollination environments $\left(\mathrm{F}_{2,515}=459.12, \mathrm{P}<0.0001\right)$, among populations within pollination environments $\left(\mathrm{F}_{4,515}=304.94, \mathrm{P}<0.0001\right)$ and among individuals within populations $\left(\mathrm{F}_{7,515}=5.57, \mathrm{P}<0.0001\right)$. The variation range of corolla tube length was greater within the native hummingbird-pollination environment than that of both non-native pollination environments and completely encompassed them (Fig. 4). Native populations significantly differ in corolla tube length: plants from Embarcación showed the shortest corolla tubes; plants from Piedra Pintada showed tubes of intermediate length and plants from Tupiza showed the largest corolla tubes. The latter native population also showed the highest variation in this floral trait (Fig. 4). Corolla tube length of plants 
318 from both non-native populations of South Africa (Buffels River and Troe Troe River; sunbird-

319 pollination) did not differ from each other or from that of plants from the native population of

320 Embarcación. Plants from the non-native Mallorcan (i.e. without pollinators) populations of

321 Biniamar and Génova showed values of corolla tube length lower than, and similar to, those of the

322 native population Piedra Pintada, respectively (Fig. 4).

323

324 Selection on flower traits

325 In the selection analyses, we observed significant gradients (linear, non-linear and/or correlational)

326 through both fitness measures in populations of the three studied pollination environments (Fig. 5,

327 Supplementary Material S1).

328 Through fruit set, we detected negative directional selection on corolla tube length in the

329 native population Embarcación (Fig. 5a): plants with shortest corolla tube length attained higher

330 reproductive success (Fig. 6a). We detected stabilizing selection on PC2 in the native population

331 Piedra Pintada and in the non-native population Biniamar (Fig. 5b and 6b,c), indicating that plants

332 with a flower shape similar to the population mean (straight and wide in Piedra Pintada, and curved

333 and narrow in Biniamar) reached higher reproductive success. We also detected correlational

334 selection between PC1 and PC2 in Biniamar (Fig. 5c). The selection surface (Fig. 7a) showed that

335 the most successful plants had low values of PC1 (i.e., wide corolla tubes) and medium or high

336 values of PC2 (i.e., similar shapes to the population mean and more curved and narrower than the

337 population mean).

338 Through seed number per fruit, we detected negative directional selection on corolla tube

339 length in Tupiza and positive directional selection on such trait in Biniamar (Fig. 5d and 6d,e).

340 Negative directional selection on PC1 (Fig. 5d) favored plants with flowers wider than the 
341 population mean in Génova (Fig. 6f). We detected negative directional selection on PC2 in Buffels

342 River (Fig. 5d), favoring plants with straighter and broader corolla tubes than the population mean

343 (Fig. 6g). We detected correlational selection through seed number per fruit between PC2 and

344 corolla tube length both in the native population Piedra Pintada and the non-native population

345 Génova (Fig. 5f). The selection surface in Piedra Pintada showed that the most successful plants

346 had slightly high PC2 values (i.e., curved and narrow corolla tubes) and near average or greater

347 corolla tube lengths (Fig. 7b). The selection surface in Génova showed that the most successful

348 plants had low PC2 values (i.e., straight and wide corolla tubes) and short corolla tubes (Fig. 7c).

349 We examined variation in selection patterns among populations by testing the significance

350 of interaction terms between population and flower traits (Table 3). We found significant

351 interactions between directional selection on corolla tube length and population through both

352 fitness measures (i.e. fruit set and seed number per fruit). For directional selection on PC2, we only

353 found a marginally significant interaction with population through seed number per fruit.

354 Correlational selection involving PC2 and corolla tube length varied among populations in a

355 marginally significant way through seed number per fruit. We did not find any significant

356 interaction between selection on PC1 and population.

358 Discussion

359 Variation in flower shape and length

360 Significant levels of phenotypic differentiation found in both corolla shape and length among 361 native and non-native areas with heterogeneous pollinator assemblages suggest that the pollination

362 context might be an important selection factor. However, trait divergence is also expected due to

363 the effect of random subsampling during colonization of novel areas, i.e. drift, but in this case we 
would not expect a match with the pollination environment. Genetic drift occurring during the process of invasion could also be the cause of the loss of variation in both non-native areas (Charlesworth 2003; Dlugosch and Parker 2008; Charlesworth et al 2009; Colautti et al 2010). In addition, the exclusively autonomous reproduction of the Mallorcan populations (Issaly et al 2020) could also lead to a reduction in phenotypic variation.

The high floral variation found among populations within the native range probably suggests the effects of divergent selection mediated by the different pollinator assemblages. In this sense, taking into account different bill lengths of hummingbird species that visit $N$. glauca flowers (Table 2), differences in pollinator assemblages could explain the remarkable variation in corolla length found among populations within the native environment. In fact, native populations with the shortest (Embarcación) and longest (Tupiza) flowers only received visits from a hummingbird with short (Sappho sparganura) and long bill (Patagona gigas), respectively (see Table 2). In addition, in the Piedra Pintada population, with a pollinator assemblage including three hummingbird species of short and long bills, plants presented flowers intermediate in corolla length. These results agree with previous studies on $N$. glauca in the native range (Nattero et al 2011) and in non-native hummingbird-pollinated populations (Schueller 2007), suggesting that corolla tube length constitutes a pollinator-matching trait in this species. Indirectly, our results suggest that corolla length and shape are not correlated, at least in the native range, because Tupiza showed the longest flowers whereas Piedra Pintada exhibited the widest ones. Only in one non-native population from South Africa (Buffels River) did flower length match the bill length of its most abundant pollinator (i.e., Nectarinia famosa, see Table 2). The fact that flower length does not vary between the South African populations is possibly, in part, because pollinator assemblages of both sites involve the same sunbird species, although in different proportions. In addition, their similarity could be due 
387 to a similar origin or to gene flow among populations. In a partial disagreement with our

388 expectations, plants in non-native populations without pollinators did not show the shortest corolla 389 tubes, although they had proportionally narrower flowers than most populations with pollinators.

390 Selection on other floral traits that reduce costs of attraction and reward to pollinators is also 391 expected in the non-native range where local pollinators are absent (Jiménez-Lobato et al 2018). 392 In this sense, nectar volume and sugar concentration differences between Mallorcan, South African 393 and native populations will be subject of future studies in this system.

Unlike flower length and width (PC1), whose variations in non-native populations fell 395 within the range of variation of native populations, corolla curvature (PC2) showed a novel variant in both non-native areas with respect to the studied native populations. As we expected, individuals from the native populations presented flowers with straight corolla tubes, while individuals from 398 all non-native populations presented curved corolla tubes. The fact that hummingbirds at the study populations have straight beaks while the Old World nectar-feeding passerines have relatively 400 curved bills (Paton and Collins 1989; Fig. 2) might explain differences in flower curvature between the native and the South African ranges (Temeles et al 2009). Our result is consistent with that 402 found in another species, where corolla shape varied between populations with different functional pollinator groups (Gómez et al 2008). The curved and relatively narrow corolla tubes found in nonnative sites without pollinators could facilitate delayed self-pollination (sensu Lloyd and Schoen 1992), that is, when corolla and stamens detach from the gynoecium at the end of anthesis. Consistent with this idea, a previous study on California islands colonized by N. glauca (Schueller 407 2004) found the presence of bent or severely crumpled corollas associated with a higher frequency of spontaneous autogamy. Alternatively, taking into account that corolla curvature improves flower 409 handling during hawkmoth visits (Campos et al 2015), curved and proportionally narrow corollas 
410 in Mallorcan populations could favor pollination by the occasional visitor Macroglossum

411 stellatarum. In addition, a study across eight species of Nicotiana showed that differences in corolla

412 shape influence flower choice by hawkmoths (Kaczorowski et al 2012). However, instead of being

413 a product of convergent adaptation to their respective pollination environments, a possible

414 explanation for the similarly curved flowers in Mallorca and South Africa is that populations in

415 one of these areas derived from populations in the other, or that both derived from a shared ancestral

416 population outside our study area with curved-flowered plants. Moreover, although part of the

417 variation found in non-native habitats is within the whole range of native populations, there is a

418 chance that those average phenotypes have different origin (e.g. from different native populations).

419 The ongoing genetic work will be very insightful in this regard because it will allow us to assess

420 the genealogy of non-native populations. In addition, genetic analyses will be able to demonstrate

421 whether non-native populations have lower genetic variation (expected by drift and selection, but

422 unexpected if multiple introductions have occurred).

424 Phenotypic selection

425 Our results showed significant selection gradients for the three studied floral traits (PC1 and PC2 426 of floral shape, and corolla tube length) in some native and non-native populations across the three

427 pollination environments. Despite the higher phenotypic variation found within native populations

428 whereupon natural selection can act, we detected a higher number of significant selection gradients

429 in non-native populations. This result is expected if adaptation to the new environment is still

430 incomplete. The fact that current reproductive success of $N$. glauca on both non-native ranges is

431 pollen-limited (Issaly et al 2020) enhances opportunities for selection via female function. We

432 found significant gradients through both measures of female reproductive success, with a higher 

453 (Schueller 2007).

number of significant gradients detected through the number of seeds per fruit, suggesting that the effectiveness of pollination affects female fitness more than the proportion of flowers pollinated. Flower length was the target of selection in five of the seven studied populations, in directional fashion in three of them, and in correlational fashion with PC2 in two populations. In addition, this was the only trait accounting for variation in selection among populations, which was apparent for directional selection through both female fitness measures. Selection favored flowers with corollas shorter than population means in two native populations, although through different fitness measures in each of them. In both cases, population mean corolla length (Figure 3) was higher than bill length of the respective hummingbird pollinators (Table 2), which would explain the negative directional selection pattern found on this trait. Directional selection on flower length was previously reported for native (Nattero et al 2010a) and non-native populations of $N$. glauca pollinated by hummingbirds (Schueller 2007). Contrary to our expectations, we found selection favoring longer corollas in one population and proportionally wider corolla tubes (i.e., lower values of PC1) in the other population of the without pollinators' environment. The occasional visitor $M$. stellatarum did not appear to influence such selection patterns, since the selected corolla length greatly exceeds the length of its proboscis (Faucheux 2013). Instead, longer corollas, together with curved tubes, could facilitate delayed self-pollination in non-native sites without pollinators. Alternatively, selection patterns in this invaded area might be the product of selection unrelated to pollination, as longer and wider flowers structurally allow larger fruits and, therefore, more seeds per fruit, which could improve dispersal success and colonization of the introduced plants

Unlike corolla width (i.e., PC1 of flower shape), which was under selection in only one non-native population of Mallorca, corolla curvature (i.e., PC2) was the target of selection both in 
native and non-native populations and in all three pollination environments. Contrary to our expectations, selection favored straight corollas in a non-native sunbird-pollinated population, but stabilizing selection (which would maintain the match between flower shape and pollination environment) was observed in a native and a non-native population without pollinators (i.e., straight and curved corollas, respectively). The evolution of corolla tube curvature also seems to be correlated with the evolution of other traits, as significant correlational selection gradients involved it in combination with corolla length in two populations (one native and one non-native), and with corolla width in one non-native population. The selection on trait combinations only partially agreed with that expected according to the pollination environments. For example, in the Mallorcan population Génova, straight and short corolla tubes where favored, but only the latter pattern agreed with our predictions for the non-native environment without pollinators.

\section{Correspondence between phenotypic differentiation and the spatial variation in selection}

Most of the spatial variation found in corolla length and shape supported our expectations based on the pollinator environments. Patterns of phenotypic selection were consistent with floral trait differentiation and with our predictions in some populations. For example, we found negative directional selection on flower length in two native populations (i.e., Tupiza and Embarcación), where the mean value of this flower trait was below the fitness optimum predicted from the corresponding pollinator bill length. In addition, we found stabilizing selection on corolla shape in a native (Piedra Pintada) and a non-native population (Biniamar), where straight and curved floral tubes, respectively, matched the expected patterns according to their pollination environments. However, selection patterns did not meet all our expectations. In various cases, we did not detect selection on corolla shape or length, while in others the selection patterns found were not 
479 consistent with either floral trait variation or with our predictions. Similarly, another study in $N$. 480 glauca found that selection on corolla length did not explain island-mainland differences in this 481 floral trait in the USA (Schueller 2007). The lack of a correspondence between phenotypic 482 differentiation and selection on floral traits could be because our estimates of natural selection are 483 based on only a single episode of reproduction in a perennial species, not lifetime reproductive 484 success (Endler 1986). In this sense, long-term stability of the selective scenarios is highly unlikely, 485 especially in the invaded range. In addition, selection on floral traits via female function often varies between years (e.g. Conner et al 1996; Caruso et al 2003; Benitez-Vieyra et al 2012), which 487 will impede the response to selection. Alternatively, low heritability could also explain the lack of a response to selection. Although there is significant heritability for corolla length, width and shape 489 in some species (Campbell 1996; Gómez et al 2009), heritability is environment-dependent 490 (Falconer and Mackay 1996) and may be lower in certain populations.

491 On the other hand, instead of being a product of selection, differences in corolla length and 492 shape among plants of native and non-native populations may be the result of plastic responses to 493 their abiotic environment (Camargo et al 2017). In this sense, given that water stress can reduce 494 flower size (e.g. Carroll et al 2001), primarily because the water cost of large flowers is high (Galen 495 et al 1999), non-native populations in South Africa may have the shortest flowers only because 496 they are growing in the driest environments (see Table 1). Both heritability and phenotypic 497 plasticity of $N$. glauca floral traits are subjects of an ongoing study in native and non-native 498 populations.

Although the reduction in phenotypic variation observed in all non-native populations 500 might reveal the random loss and fixation of alleles in small founding populations (Charlesworth 501 2003; Dlugosch and Parker 2008; Charlesworth et al 2009), it is unlikely that the apparently 
502 adaptive differences in corolla length and shape among geographical areas are due to stochastic 503 processes such as drift. Instead, the match between floral traits and their pollination environments 504 suggests that current differences in corolla length and shape would seem more likely to reflect a 505 response to varying selection pressures under different pollinator regimes. Selection is likely to 506 vary over time and may have been stronger during a period of pollinator or mate scarcity, such as

507 when $N$. glauca first arrived on non-native areas. It is very difficult to reveal the driving force of 508 long-term adaptation by studying a single selection event.

509

510 Acknowledgements

511 AAC, ANS, SBV and VP acknowledge the National Research Council of Argentina (CONICET)

512 and the Universidad Nacional de Córdoba (UNC) as researchers. We thank the two anonymous

513 reviewers, and associated editor for their valuable suggestions; we also thank MC Baranzelli, G

514 Bertone, R Castro, A Coetzee, MC Díaz-Vélez, MC Maubecin, X Rotllán Puig, C Tur, and C 515 Vignolo for assistance in the field work, and C Vignolo and F Gilles for assistance in the lab. This 516 work was supported by FONCyT (PICT 2015-3089; PICT-2011-0837) to ANS, the Department 517 of Science and Technology of South Africa (438 75946) and the Spanish Ministry of Economy and 518 Competitiveness (CGL2013-44386-P). The authors declare no conflicts of interest. 
519

520

521

522

523

524

525

526

527

528

529

530

531

532

533

534

535

536

537

538

539

540

541

\section{References}

Benítez-Vieyra S, Medina AM, Cocucci AA (2009) Variable selection patterns on the labellum shape of Geoblasta pennicillata, a sexually deceptive orchid. J Evol Biol 22:2345-2362

Benítez-Vieyra S, Glinos E, Medina AM et al (2012) Temporal variation in the selection on floral traits in Cyclopogon elatus (Orchidaceae). Evol Ecol 26:1451-1468

Bodbyl Roels SA, Kelly JK (2011) Rapid evolution caused by pollinator loss in Mimulus guttatus. Evolution 65(9):2541-2552.

Bookstein FL (1997) Morphometric tools for landmark data: geometry and biology. Cambridge University Press, Cambridge.

Brodie E III, Moore A, Janzen F (1995) Visualizing and quantifying natural selection. Trends Ecol Evol 10(8):313-318

Bromilow C (2001) Problem Plants of South Africa. Briza Publications, Pretoria.

Camargo ID, Nattero J, Careaga SA, Núñez-Farfán J (2017) Flower-level developmental plasticity to nutrient availability in Datura stramonium: implications for the mating system. Ann Bot 120(4):603-615

Campbell DR (1996) Evolution of floral traits in a hermaphroditic plant: field measurements of heritabilities and genetic correlations. Evolution 50(4):1442-1453

Campos EO, Bradshaw HD, Daniel TL (2015) Shape matters: corolla curvature improves nectar discovery in the hawkmoth Manduca sexta. Func Ecol 29:462-468

Carroll AB, Pallardy SG, Galen C (2001) Drought stress, plant water status, and floral trait expression in fireweed, Epilobium angustifolium (Onagraceae). Am J Bot 88(3):438-446

Caruso CM, Peterson SB, Ridley CE (2003) Natural selection on floral traits of Lobelia (Lobeliaceae): spatial and temporal variation. Am J Bot 90(9):1333-1340 
542 Caruso CM, Eisen KE, Martin RA et al (2019) A meta- analysis of the agents of selection on floral $543 \quad$ traits. Evolution 73(1):4-14

544 Charlesworth B, Morgan MT, Charlesworth D (1991) Multilocus models of inbreeding depression 545 with synergistic selection and partial self-fertilization. Genet Res 57(2):177-194

546 Charlesworth D (2003) Effects of inbreeding on the genetic diversity of populations. Philos T Roy $547 \quad$ Soc B 358(1434):1051-1070

548 Charlesworth D, Willis JH (2009) The genetics of inbreeding depression. Nat Rev Genet 549 10(11):783-796

550 Colautti RI, Eckert CG, Barrett SC (2010) Evolutionary constraints on adaptive evolution during 551 range expansion in an invasive plant. . P Roy Soc B-Biol Sci 277(1689):1799-1806

552 Colautti RI, Lau JA (2015) Contemporary evolution during invasion: evidence for differentiation, 553 natural selection, and local adaptation. Mol Ecol 24(9):1999-2017

554 Conner JK, Rush S, Jennetten P (1996) Measurements of natural selection on floral traits in wild 555 radish (Raphanus raphanistrum). I. Selection through lifetime female fitness. Evolution

556 50(3):1127-1136

557 Cronk QCB, Fuller JL (1995) Invasive plants: the threat to natural ecosystems worldwide. 558 Chapman \& Hall, London

559

560

561

562

563 564

Dixon PM (1993) The bootstrap and the jackknife: describing the precision of ecological indices. In: Scheiner SM, Gurevitch J (eds) Design and analysis of ecological experiments. Chapman \& Hall, New York, pp 290-318

Dlugosch KM, Parker IM (2008) Founding events in species invasions: genetic variation, adaptive evolution, and the role of multiple introductions. Mol Ecol 17:431-449

Endler JA (1986) Natural selection in the wild. Princeton University Press, Princeton 
565 Falconer DS, Mackay TFC (1996) Inbreeding and crossbreeding. In: Introduction to quantitative 566 genetics. Longman Group Ltd, Essex, pp 247-262

567 Faucheux MJ (2013) Sensillum types on the proboscis of the Lepidoptera: a review. Ann Soc $568 \quad$ Entomol Fr 49(1):73-90

569 Fenster CB, Ritland K (1994) Evidence for natural selection on mating system in Mimulus $570 \quad$ (Schrophulariaceae). Int J Plant Sci 155:588-596

571 Fishman L, Willis JH (2008) Pollen limitation and natural selection on floral characters in the 572 yellow monkeyflower, Mimulus guttatus. New Phytol 177(3):802-810

573 Galen C (1999) Why do flowers vary? Bioscience 49(8):631-640

574 Galetto L, Bernardello L (1993) Nectar secretion pattern and removal effects in three species of $575 \quad$ Solanaceae. Can J Bot 71:1394-1398

576 Geerts S, Pauw A (2009) African sunbirds hover to pollinate an invasive hummingbird-pollinated $577 \quad$ plant. Oikos 118:573-579

578 Gómez JM, Zamora R (2000) Spatial variation in the selective scenarios of Hormathophylla $579 \quad$ spinosa (Cruciferae). Am Nat 155:657-668

580 Gómez JM, Bosch J, Perfectti F et al (2008) Spatial variation in selection on corolla shape in a 581 generalist plant is promoted by the preference patterns of its local pollinators. P Roy Soc $582 \quad$ B-Biol Sci 275:2241-2249

583 Gómez JM, Abdelaziz M, Muñoz-Pujares J, Perfectti F (2009) Heritability and genetic correlation 584 of corolla shape and size in Erysimum mediohispanicum. Evolution 63:1820-1831

585 Goodspeed TH (1954) The genus Nicotiana. Chronica Botanica Co, Massachusetts

586 Gunz P, Mitteroecker P (2013) Semilandmarks: a method for quantifying curves and surfaces.

$587 \quad$ Hystrix 24(1):103-109 
588 Herrera CM, Castellanos MC and Medrano M (2006) Geographical context of floral evolution:

589

590

591

592

593

594

595

596

597

598

599

600

601

602

603

604

605

606

607

608

609

610

towards an improved research programme in floral diversification. In: Harder LD, Barrett SCH (eds) Ecology and evolution of flowers. Oxford University Press, Oxford, pp 278-294

Hierro JL, Maron JL, Callaway RM (2005) A biogeographical approach to plant invasions: the importance of studying exotics in their introduced and native range. $\mathrm{J}$ Ecol 9:5-15

Issaly EA, Sérsic AN, Pauw A et al (2020) Reproductive ecology of the bird-pollinated Nicotiana glauca across native and introduced ranges with contrasting pollination environments. Biol Invasions 22:485-498

Jiménez-Lobato V, Martínez-Borda E, Núñez-Farfán J et al (2018) Changes in floral biology and inbreeding depression in native and invaded regions of Datura stramonium. Plant Biol 20:214-223

Kaczorowski RL, Seliger AR, Gaskett AC et al (2012) Corolla shape vs. size in flower choice by a nocturnal hawkmoth pollinator. Funct Ecol 26(3):577-587

Kingsolver JG, Pfennig DW (2007) Patterns and power of phenotypic selection in nature. Bioscience 57(7):561-572

Klingenberg CP (2011) MorphoJ: an integrated software package for geometric morphometrics. Mol Ecol Resour 11:353-357

Lande R, Arnold SJ (1983) The measurement of selection on correlated characters. Evolution $37: 1210-1226$

Lloyd DG (1987) Allocations to pollen, seeds and pollination mechanisms in self-fertilizing plants. Funct Ecol 1:83-89

Lloyd DG, Schoen DJ (1992) Self- and cross-fertilization in plants. I. Functional dimensions. Int J Plant Sci 153(3):358-369 
611 Maad J, Alexandersson R (2004) Variable selection in Platanthera bifolia (Orchidaceae):

612

613

614

615

616

617

618

619

620

621

622

623

624

625

626

627

628

629

630

631

632

633

phenotypic selection differed between sex functions in a drought year. J Evol Biol 17(3):642-650

Mitchell-Olds T, Shaw R (1987) Regression analysis of natural selection: statistical inference and biological interpretations. Evolution 41(6):1149-1161

Moeller DA (2006) Geographic structure of pollinator communities, reproductive assurance, and the evolution of self-pollination. Ecology 87:1510-1522

Molina-Montenegro MA, Quiroz CL, Torres-Díaz C et al (2011) Functional differences in response to drought in the invasive Taraxacum officinale from native and introduced alpine habitat ranges. Plant Ecol Divers 4:37-44

Moragues E, Rita J (2005) Els vegetals introduïts a les Illes Balears. Govern de les Illes Balears, Palma de Mallorca

Murren CJ, Chang CC, Dudash MR (2009) Patterns of selection of two North American native and nonnative populations of monkeyflower (Phrymaceae). New Phytol 183:691-701

Nattero J, Cocucci AA (2007) Geographical variation in floral traits of the tree tobacco in relation to its hummingbird pollinator fauna. Biol J Linn Soc 90:657-667

Nattero J, Sérsic AN, Cocucci AA (2010a) Patterns of contemporary phenotypic selection and flower integration in the hummingbird-pollinated Nicotiana glauca between populations with different flower-pollinator combinations. Oikos 119:852-863

Nattero J, Cocucci AA, Medel R (2010b) Pollinator-mediated selection in a specialized pollination system: matches and mismatches across populations. J Evolution Biol 23:1957-1968

Nattero J, Sérsic AN, Cocucci AA (2011) Geographic variation of floral traits in Nicotiana glauca: Relationships with biotic and abiotic factors. Acta Oecol 37:503-511 
634 Núñez-Farfán J, Schlichting CD (2005) Natural selection in Potentilla glandulosa revisited. Evol $635 \quad$ Ecol Res 7(1):105-119

636 Ollerton J, Watts S, Connerty S et al (2012) Pollination ecology of the invasive tree tobacco

637 Nicotiana glauca: comparisons across native and non-native ranges. J Pollinat Ecol 9:85638 95

639

640

641

642

643

644

645

646

647

648

649

650

651

652

653

654

655

656

Palacio FX, Ordano M, Benitez-Vieyra S (2019) Measuring natural selection on multivariate phenotypic traits: a protocol for verifiable and reproducible analyses of natural selection. Isr J Ecol Evol 1(aop):1-7

Paton DC, Collins BG (1989) Consequences of differences in body mass, wing length and leg morphology for nectar-feeding birds. Aust J Ecol 14:269-289

R Core Team (2020) R: A language and environment for statistical computing. R Foundation for Statistical Computing, Vienna, Austria. Available from http://www.R-project.org/ (accessed April 2020)

Richardson DM, Allsopp N, D’Antonio CM et al (2000) Plant invasions - the role of mutualisms. Biol Rev 75:65-93

Rohlf FJ (2010) tpsDig v2. 16. Free software available. Available from http://morphometrics. org/morphmet. html (accessed May 2017)

Sakai A, Allendorf F, Holt JS et al (2001) The population biology of invasive species. Ann Rev Ecol Evol Syst 32:305-332

Schueller SK (2004) Self-pollination in island and mainland populations of the introduced hummingbird- pollinates. Am J Bot 91:672-681

Schueller SK (2007) Island-mainland difference in Nicotiana glauca (Solanaceae) corolla length: a product of pollinator mediated selection? Evol Ecol 21:81-98 
657 Sheets HD (2017) CoordGen 8. Department of Physics, Canisius College, Buffalo, USA. Available 658 from http://www3.canisius.edu/ sheets/morphsoft.html (accessed May 2017)

659 Takebayashi N, Wolf DE, Delph LF (2006) Effect of variation in herkogamy on outcrossing within 660 a population of Gilia achilleifolia. Heredity 96(2):159-165

661 Temeles EJ, Koulouris CR, Sander SE et al (2009) Effect of flower shape and size on foraging 662 performance and trade-offs in a tropical hummingbird. Ecology 90:1147-1161

663 Traveset A, Richardson DM (2014) Mutualistic interactions and biological invasions. Ann Rev $664 \quad$ Ecol Evol Syst 45:89-113

665 Warton DI, Hui FKC (2011) The arcsine is asinine: the analysis of proportions in ecology. Ecology $66692(1): 3-10$

667 Westerkamp C (1990) Bird-flowers hovering versus perching exploitation. Bot Acta 103:366-371

668 Westley PA (2011) What invasive species reveal about the rate and form of contemporary 669 phenotypic change in nature. Am Nat 177(4):496-509

670 Wood SN (2017) Generalized additive models: an introduction with R. CRC Press/Taylor \& 671 Francis Group, Boca Raton London, New York

672 Zelditch ML, Swiderski DL, Sheets HD (2012) Geometric morphometrics for biologists: a primer. $673 \quad$ Academic Press, Cambridge

674 Zuur A, Ieno EN, Walker NJ et al (2009) Mixed Effects Models and Extensions in Ecology with 675 R. Springer, New York 


\section{Figure legends}

677

678 Figure 1

679 Location of 18 landmarks used for geometric morphometric analysis of corolla tube shape in 680 Nicotiana glauca.

681

682 Figure 2

683 Pollinators of Nicotiana glauca. Hummingbirds: (a) Patagona gigas on N. glauca, (b) Sappho 684 sparganura female, (c) Chlorostilbon lucidus female. Sunbirds: (d) Cinnyris chalybeus male on 685 Protea nitida (e) Nectarinia famosa male on P. nitida, (f) Cinnyris fuscus male. Photos: A.N. Sérsic 686 (a), C.C. Maubecin (b), E.A. Issaly (c), A. Pauw (d and e), and D. Shapiro (f).

687

688 Figure 3

689 Biplot based on the Principal Component Analysis (PCA) yielded by geometric morphometric 690 analysis on the corollas of 546 Nicotiana glauca plants in three native and four non-native 691 populations. Plants (dots) are colored by population. Ellipses indicate different pollination 692 environments: dotted $=$ native hummingbird-pollination; dashed $=$ non-native sunbird-pollination; 693 solid line $=$ non-native without pollinators. The minimum and maximum scores (i.e. corolla shape) 694 of the first two PCs are shown.

695

696 Figure 4 
697 Flower length of Nicotiana glauca in the seven studied populations. Median values are indicated 698 by the perpendicular line within each box, and dots highlight outliers. Significant differences $(P<$ $6990.05)$ among populations are indicated by different letters.

700

701 Figure 5

702 Selection gradients on Nicotiana glauca floral traits through fruit set (a-c) and number of seeds per 703 fruit (d-f). Directional (a, d), quadratic (b, e) and correlational (c, f) selection gradients are 704 indicated. Bars indicate the 95\% confidence interval obtained from 10000 bootstrap replicates. 705 Populations are indicated by different colors. Stars indicate significant selection gradients. * $\mathrm{P}<$ $7060.05 ; * * \mathrm{P}<0.01 ; * * * \mathrm{P}<0.001$.

707

708 Figure 6

709 Cubic spline regressions between standardized floral traits and reproductive success in native and 710 non-native Nicotiana glauca populations where significant directional and quadratic selection 711 gradients were detected. Dotted lines correspond to \pm 1 Bayesian Standard Errors.

712

\section{$713 \quad$ Figure 7}

714 Selection surfaces, estimated through Generalized Additive Models, for pairs of traits significantly 715 affected by correlational selection in three studied populations of Nicotiana glauca. 


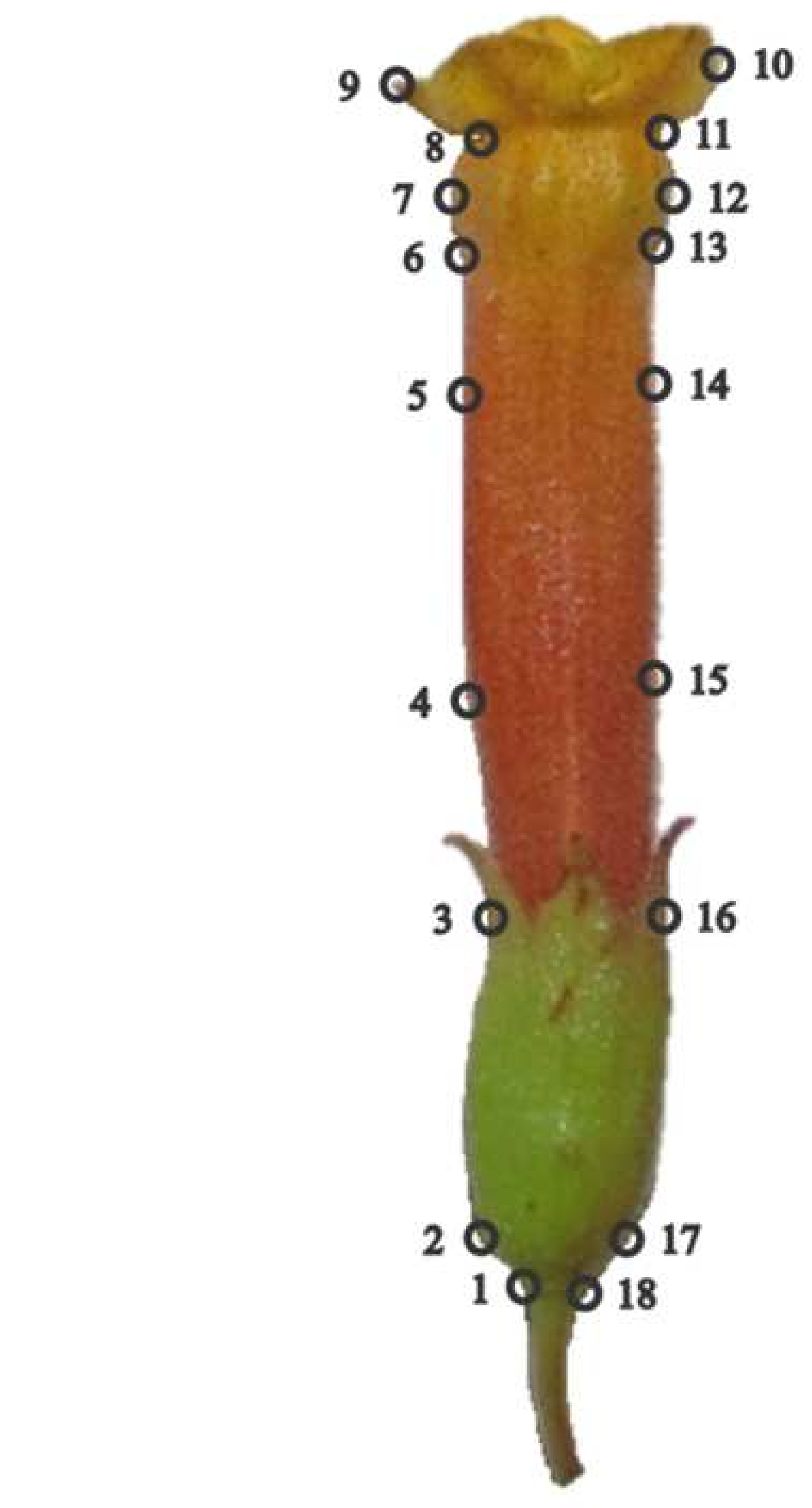




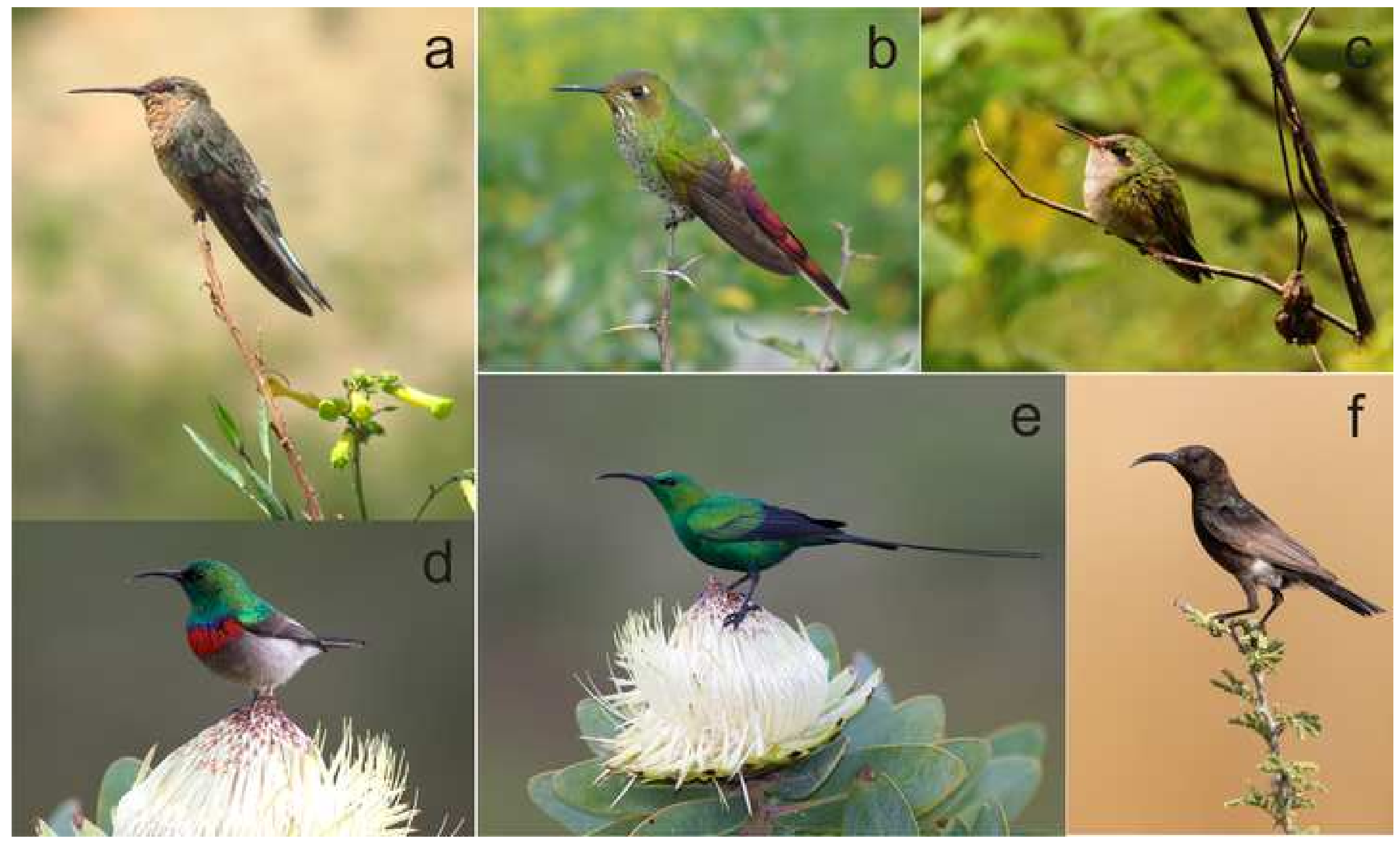




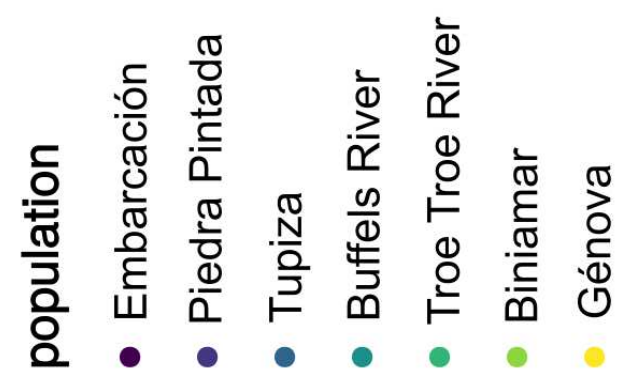
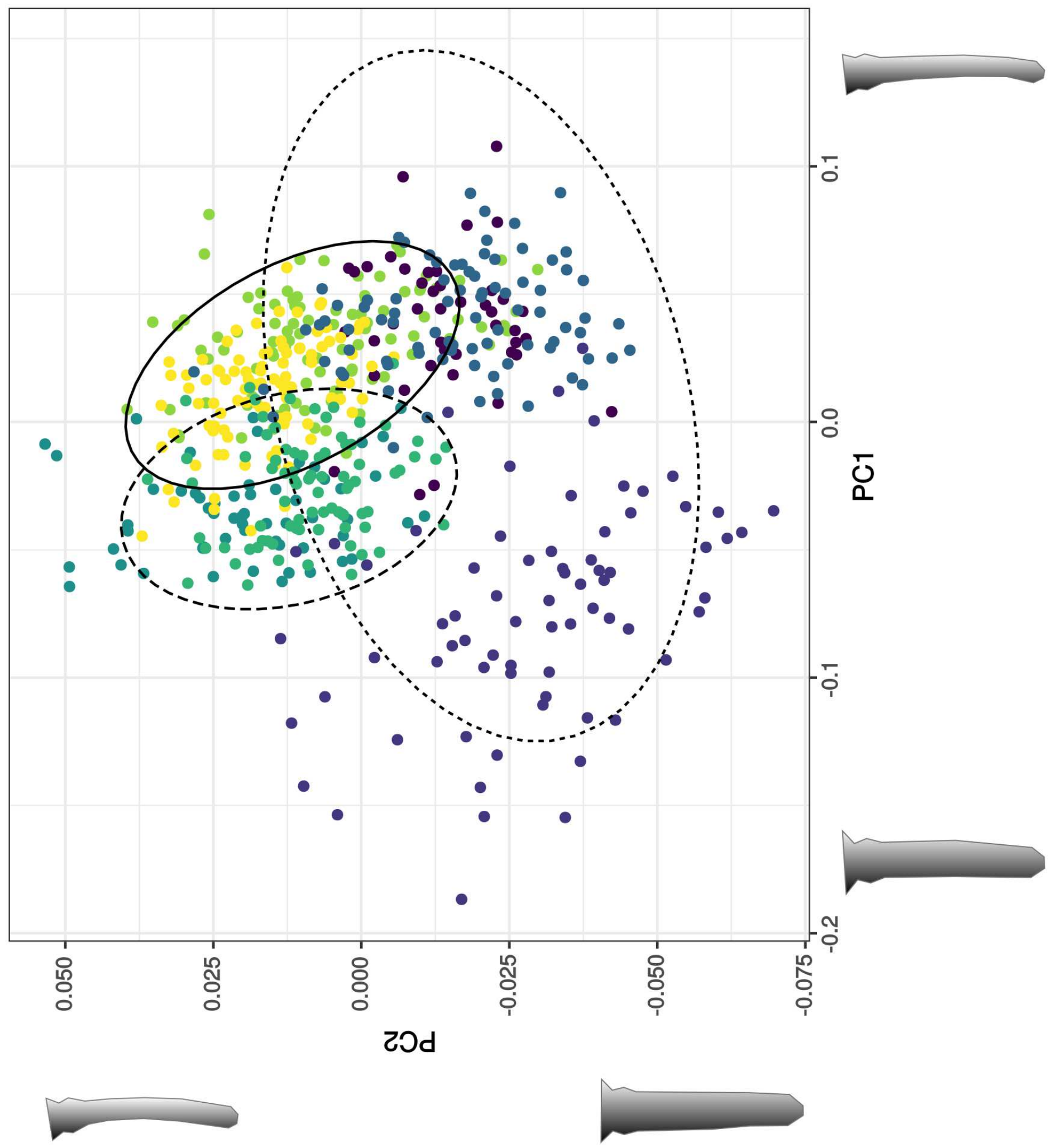
Click here to access/download;Figure;Figure 4.eps $\underline{\underline{\underline{ }}}$

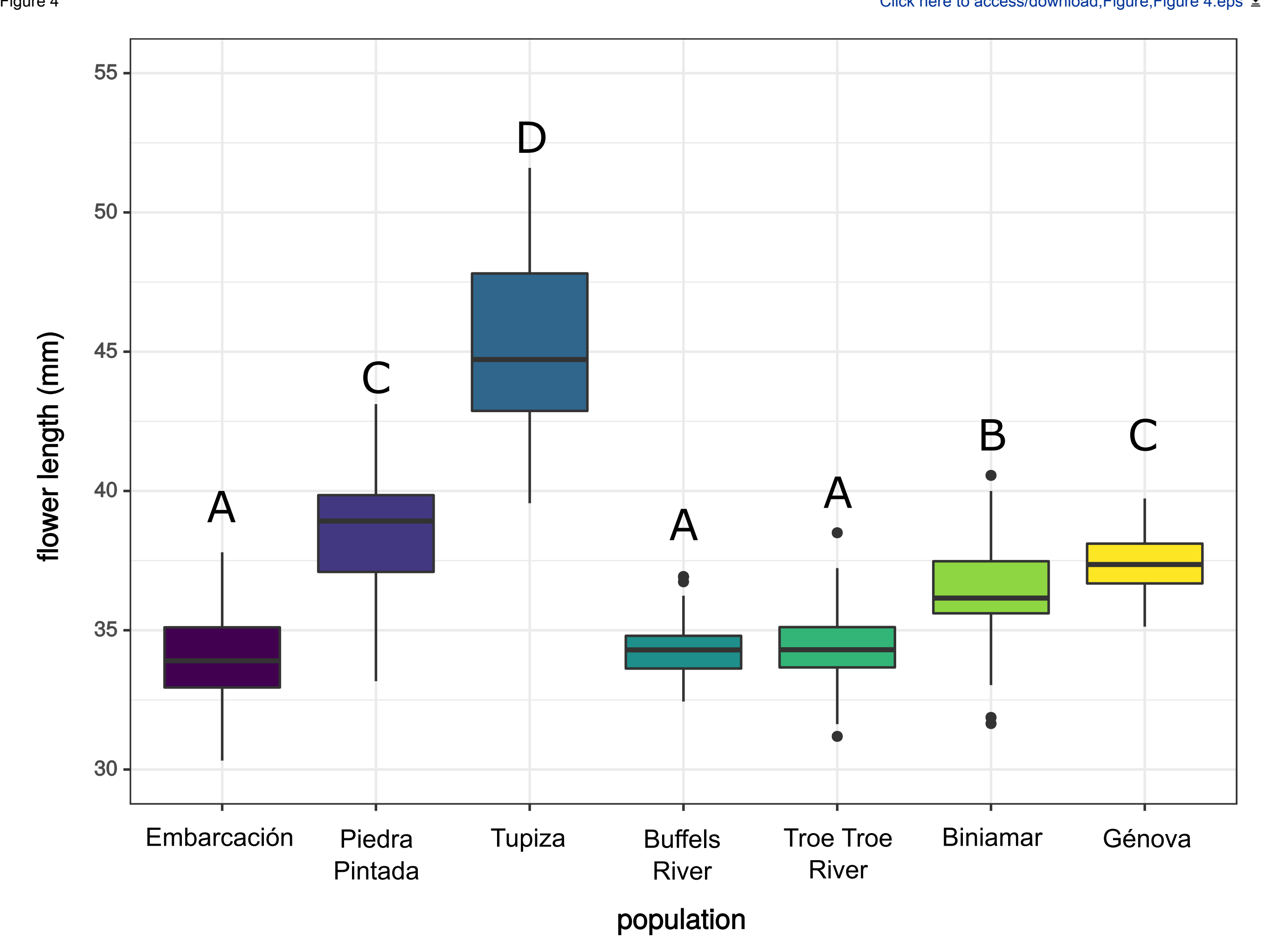



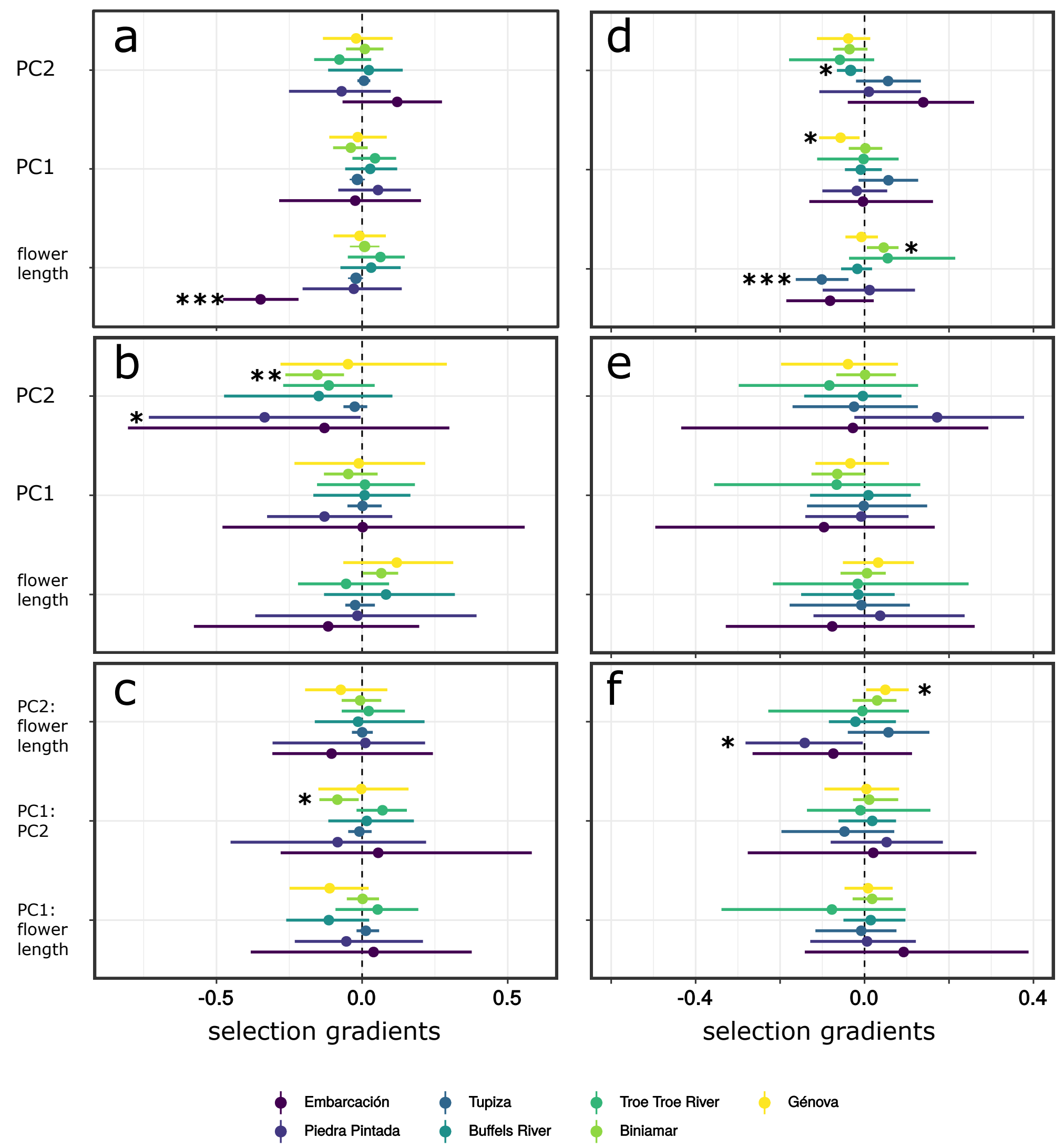

Troe Troe River

Génova

Biniamar 
Click here to access/download;Figure;Figure 6.eps $\underline{\underline{ \pm}}$

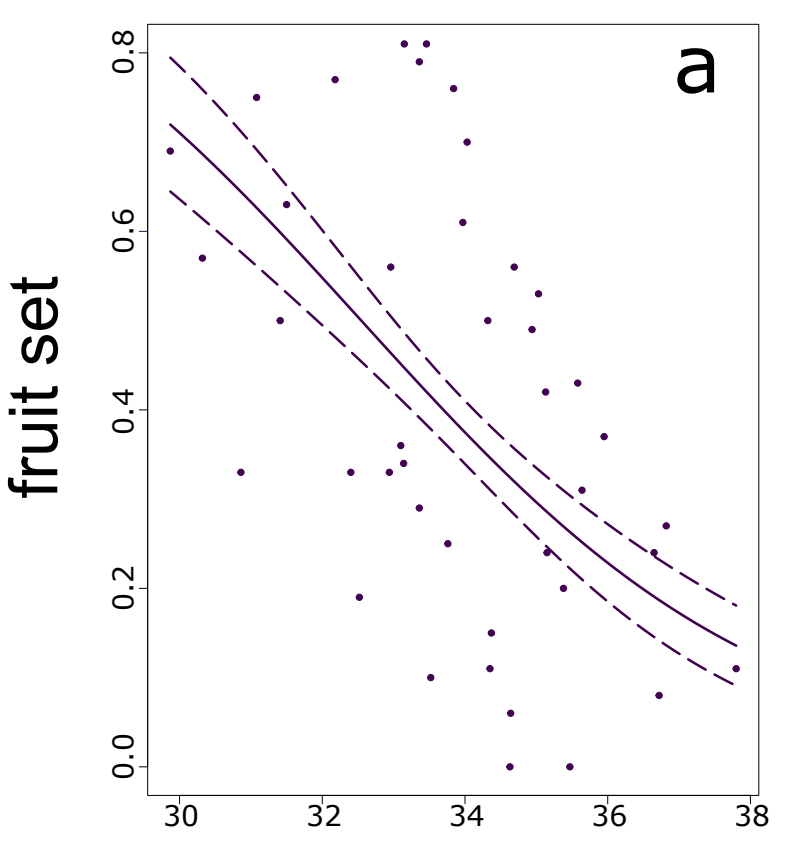

flower length

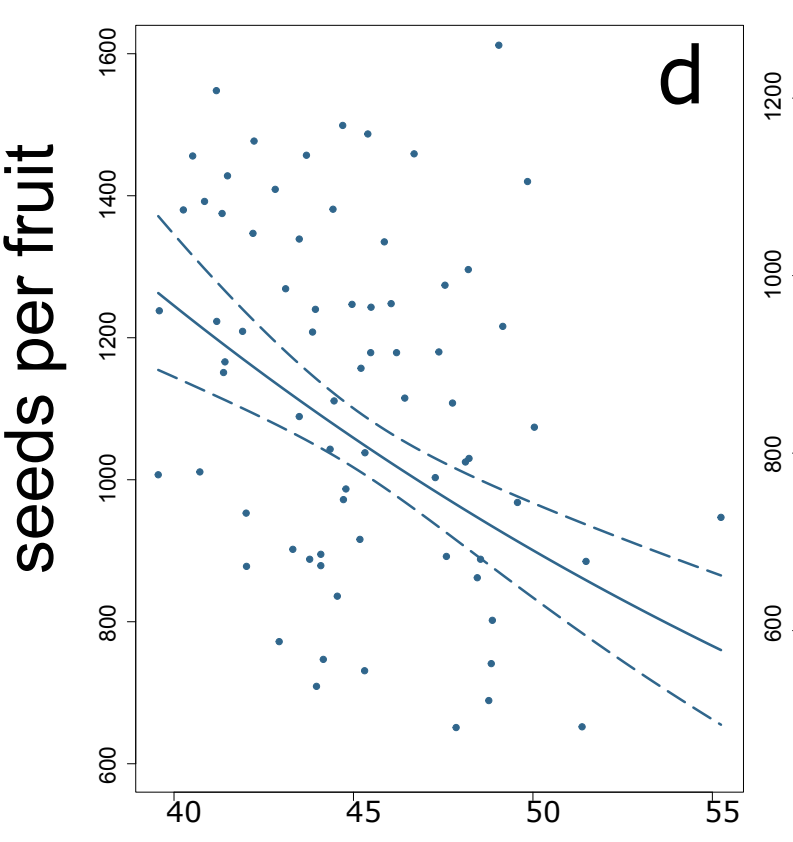

flower length

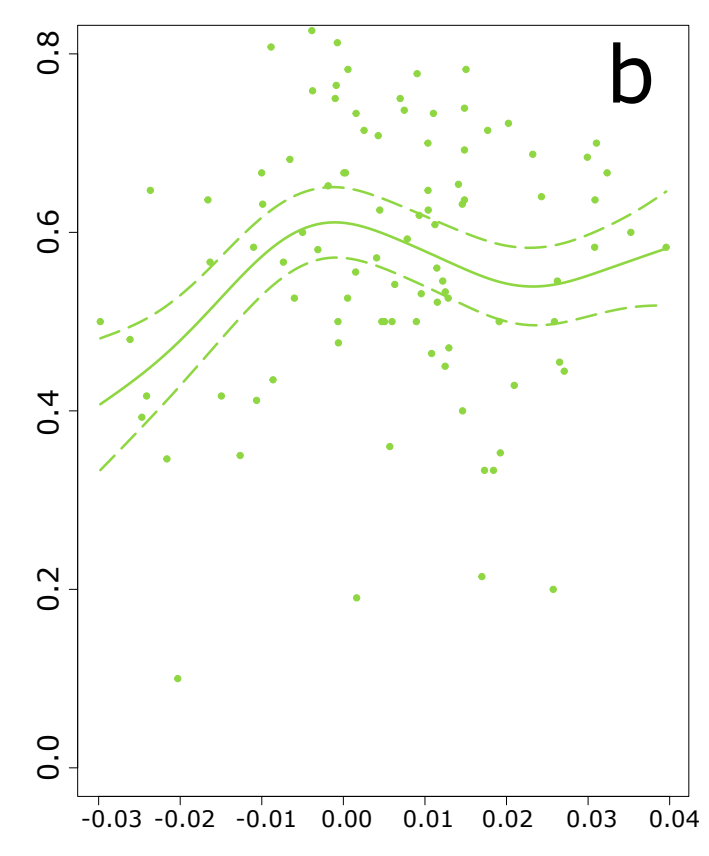

PC2

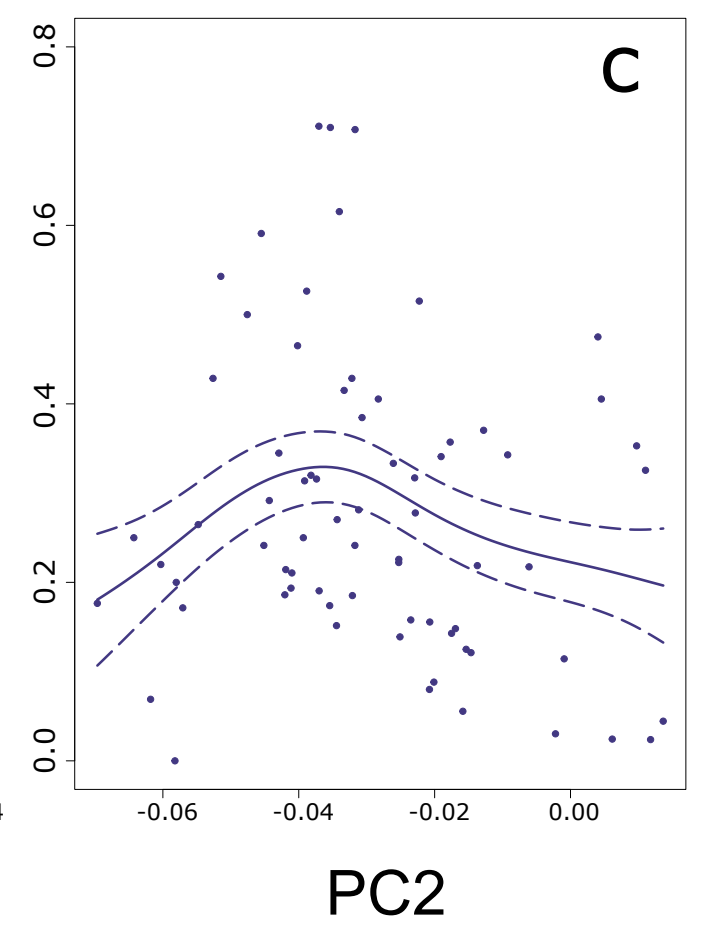

population

- Embarcación

- Piedra Pintada

- Tupiza

- Biniamar

- Génova

- Buffels River
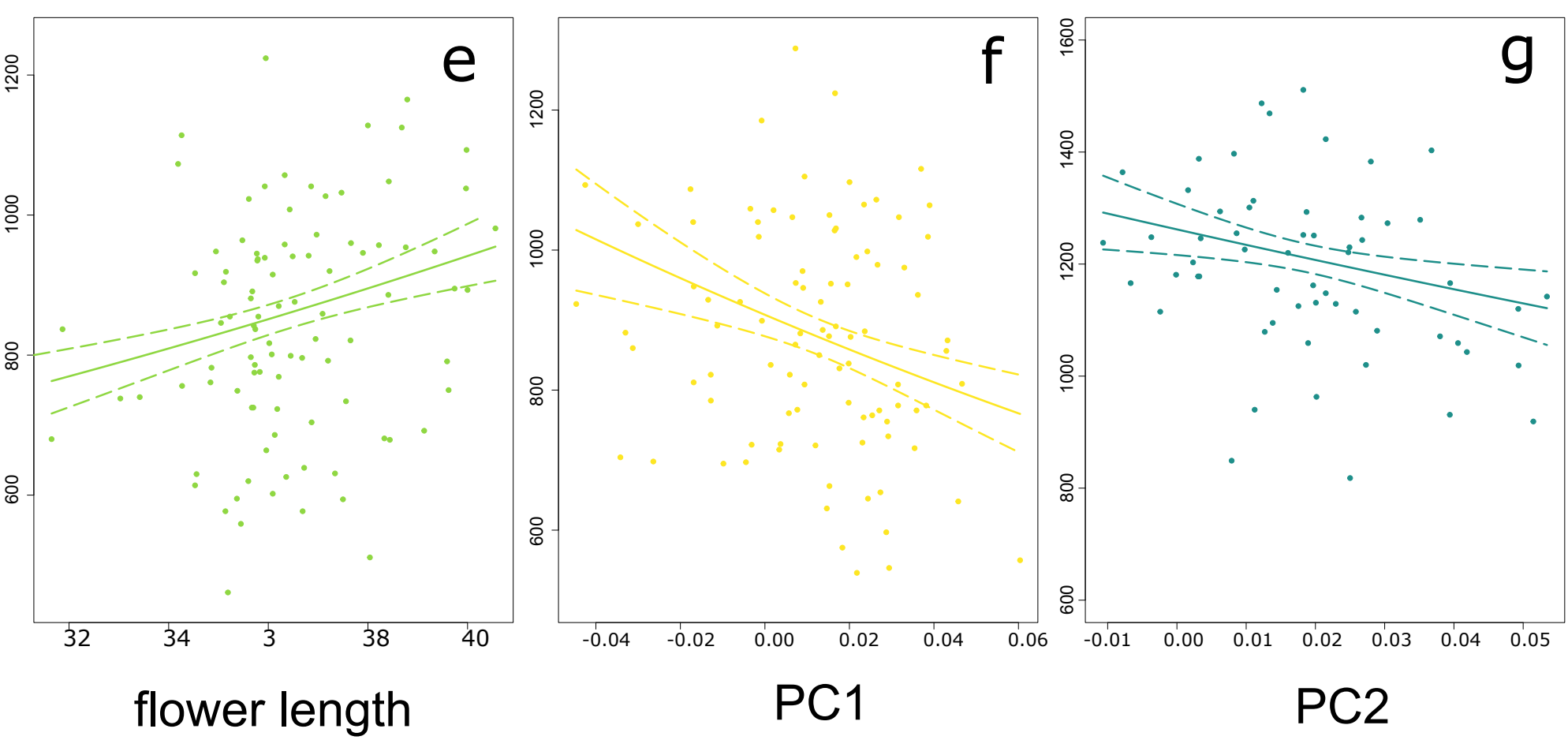
a

\section{Biniamar}

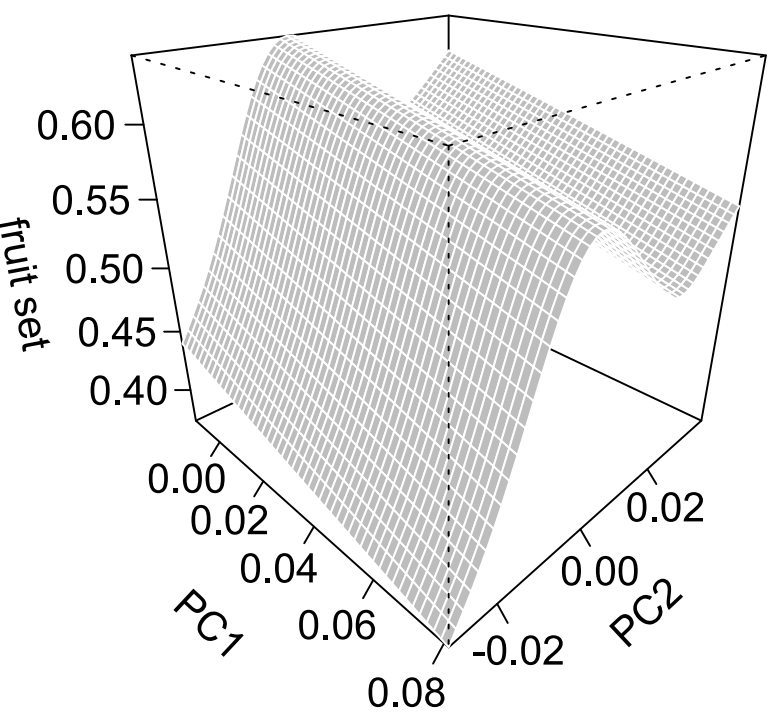

b

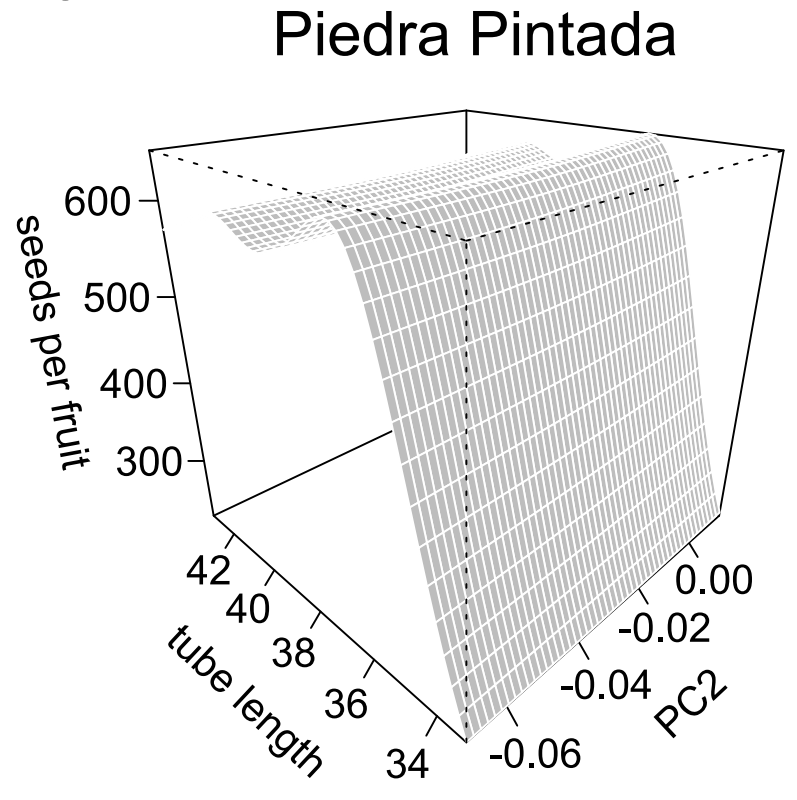

C

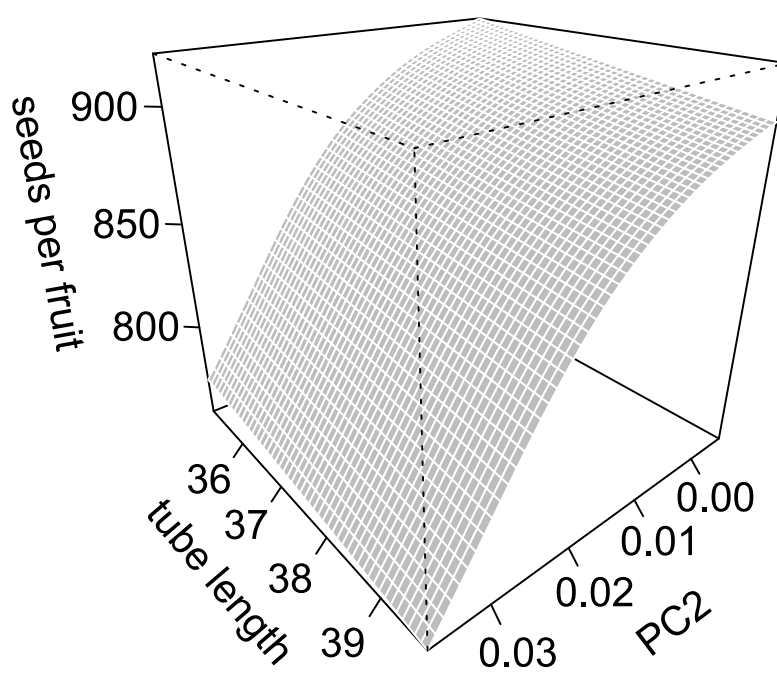

\section{Génova}


Table 1 Geographical coordinates and environmental characteristics: altitude, absolute annual precipitation (AAP), and absolute annual temperature (AAT) of the seven studied populations of Nicotiana glauca. Period of fieldwork and number of sampled plants in each population is provided.

\begin{tabular}{|c|c|c|c|c|c|c|c|c|}
\hline $\begin{array}{l}\text { Pollination environments and } \\
\text { populations }\end{array}$ & Location & Latitude & Longitude & $\begin{array}{l}\text { Altitude } \\
\qquad(\mathrm{m})\end{array}$ & $\begin{array}{l}\text { AAP } \\
(\mathrm{mm})\end{array}$ & $\begin{array}{l}\mathrm{AAT} \\
\left({ }^{\circ} \mathrm{C}\right)\end{array}$ & $\begin{array}{l}\text { Period of } \\
\text { fieldwork }\end{array}$ & $\begin{array}{c}\text { Number of } \\
\text { plants sampled } \\
\text { for } \\
\text { morphometrics }\end{array}$ \\
\hline \multicolumn{9}{|l|}{ Native hummingbird-pollination } \\
\hline Embarcación & Salta, Argentina & $23^{\circ} 14^{\prime} 40^{\prime \prime} \mathrm{S}$ & $64^{\circ} 8^{\prime} 7^{\prime \prime} \mathrm{W}$ & 310 & 692 & 17.2 & 2013 & 43 \\
\hline Piedra Pintada & $\begin{array}{l}\text { La Rioja, } \\
\text { Argentina }\end{array}$ & $29^{\circ} 25^{\prime} 46^{\prime \prime} \mathrm{S}$ & $67^{\circ} 49^{\prime} 47^{\prime \prime} \mathrm{W}$ & 1590 & 338 & 19.6 & 2012 & 75 \\
\hline Tupiza & Potosí, Bolivia & $21^{\circ} 40^{\prime} 39^{\prime \prime} \mathrm{S}$ & $65^{\circ} 34^{\prime} 43^{\prime \prime} \mathrm{W}$ & 3213 & 370 & 11.2 & 2013 & 86 \\
\hline \multicolumn{9}{|l|}{ Non-native sunbird-pollination } \\
\hline Buffels River & $\begin{array}{l}\text { Northern Cape, } \\
\text { South Africa }\end{array}$ & $29^{\circ} 43^{\prime} 13^{\prime \prime} \mathrm{S}$ & $17^{\circ} 36^{\prime} 53^{\prime \prime} \mathrm{E}$ & 201 & 105 & 18.4 & 2014 & 62 \\
\hline Troe Troe River & $\begin{array}{l}\text { Western Cape, } \\
\text { South Africa }\end{array}$ & $31^{\circ} 36^{\prime} 37^{\prime}, \mathrm{S}$ & $18^{\circ} 43^{\prime} 40^{\prime \prime} \mathrm{E}$ & 125 & 145 & 18.3 & 2014 & 80 \\
\hline \multicolumn{9}{|l|}{ Non-native without pollinators } \\
\hline Biniamar & Mallorca, Spain & $39^{\circ} 25^{\prime} 48^{\prime \prime} \mathrm{N}$ & $2^{\circ} 32^{\prime} 60^{\prime \prime} \mathrm{E}$ & 58 & 608 & 16.6 & 2012 & 100 \\
\hline Génova & Mallorca, Spain & $39^{\circ} 21^{\prime} 1^{\prime \prime} \mathrm{N}$ & $2^{\circ} 23^{\prime} 25^{\prime \prime} \mathrm{E}$ & 58 & 437 & 18.3 & 2012 & 100 \\
\hline
\end{tabular}

AAP and AAT obtained from: Worldwide Bioclimatic Classification System 1996-2015. Altitude obtained from: https://www.mapsdirections.info/coordenadasde-googlemaps.html 
Table 2 Pollinator species, percentage of visits and mean bill length (regional mean) of each pollinator species and observation time in three native and two non-native populations of Nicotiana glauca.

\begin{tabular}{|c|c|c|c|c|}
\hline $\begin{array}{l}\text { Pollination environments and } \\
\text { populations }\end{array}$ & Pollinator species & $\begin{array}{l}\text { Percentage } \\
\text { of visits }\end{array}$ & $\begin{array}{l}\text { Mean bill length } \pm \text { SD } \\
\text { (number of specimens) }\end{array}$ & $\begin{array}{l}\text { Number of } 20 \text {-min. } \\
\text { observation periods }\end{array}$ \\
\hline \multicolumn{5}{|l|}{ Native hummingbird-pollination } \\
\hline Embarcación & Sappho sparganura & 100 & $21.16 \pm 1.86(5)$ & 12 \\
\hline \multirow{3}{*}{ Piedra Pintada } & Patagona gigas & 72.4 & $44.30 \pm 1.02$ & 12 \\
\hline & Sappho sparganura & 45.9 & $21.53 \pm 2.09(7)$ & \\
\hline & Chlorostilbon lucidus & 21.8 & $19.37 \pm 0.72(6)$ & \\
\hline Tupiza & Patagona gigas & 100 & $43.89 \pm 0.86(8)$ & 15 \\
\hline \multicolumn{5}{|l|}{ Non-native sunbird-pollination } \\
\hline \multirow[t]{3}{*}{ Buffels river } & Nectarinia famosa & 66.6 & $35.83 \pm 2.53(6)$ & 10 \\
\hline & Cinnyris fuscus & 25.9 & $21.26 \pm 1.94(39)$ & \\
\hline & Cinnyris chalybeus & 7.5 & $21.22 \pm 0.83(5)$ & \\
\hline \multirow[t]{3}{*}{ Troe Troe River } & Cinnyris fuscus & 55.3 & $18.23 \pm 0.76(3)$ & 12 \\
\hline & Nectarinia famosa & 33.3 & $30.78 \pm 3.17(582)$ & \\
\hline & Cinnyris chalybeus & 11.3 & $20.27 \pm 2.99(1951)$ & \\
\hline
\end{tabular}


1 Table 3 Interaction terms from ANCOVAs between population and slopes (directional, quadratic

2 and correlational gradients) from phenotypic selection models. Significant interactions $(P<0.05$;

3 in bold) indicate that selection varied across populations.

4

\begin{tabular}{lllll}
\hline Fitness measure & Selection gradient & Source of variation & $\mathrm{F}_{(1,537)}$ & $P$ \\
\hline \multirow{2}{*}{ Fruit set } & linear & Population $\times$ PC1 & 0.81 & 0.566 \\
& linear & Population $\times$ PC2 & 1.13 & 0.344 \\
& linear & Population $\times$ corolla length & $\mathbf{5 . 2 4}$ & $<\mathbf{0 . 0 0 0 1}$ \\
& quadratic & Population $\times$ PC1 & 0.39 & 0.883 \\
& quadratic & Population $\times$ PC2 & 1.22 & 0.297 \\
& quadratic & Population $\times$ corolla length & 0.89 & 0.503 \\
& correlational & Population $\times$ PC1:PC2 & 1.11 & 0.357 \\
& correlational & Population $\times$ PC1:corolla length & 1.05 & 0.394 \\
& correlational & Population $\times$ PC2:corolla length & 0.67 & 0.677 \\
& linear & Population $\times$ PC1 & 1.20 & 0.307 \\
& linear & Population $\times$ PC2 & 2.09 & 0.053 \\
& linear & Population $\times$ corolla length & $\mathbf{2 . 1 3}$ & $\mathbf{0 . 0 4 9}$ \\
& quadratic & Population $\times$ PC1 1 & 0.27 & 0.950 \\
& quadratic & Population $\times$ PC2 & 1.17 & 0.324 \\
& quadratic & Population $\times$ corolla length & 0.20 & 0.977 \\
& correlational & Population $\times$ PC1:PC2 & 0.28 & 0.945 \\
& correlational & Population $\times$ PC1:corolla length & 0.64 & 0.700 \\
& correlational & Population $\times$ PC2:corolla length & 2.04 & 0.059 \\
\hline
\end{tabular}

5 
Click here to access/download Supplementary Material S1.xlsx 